\title{
Judicialização da política: a atuação dos governadores do estado de Santa Catarina por meio de ações de ADPF junto ao Supremo Tribunal Federal
}

\author{
Carla Simon* \\ Luciene Dal Ri**
}

\section{INTRODUÇÃO}

A judicialização da política é um fenômeno relativamente recente, tendo ocorrido no Brasil após a promulgação da Constituição Federal de 1988. Devido à expansão e à amplitude das pretensões constitucionalizadas, diversos temas que até então pertenciam apenas ao ambiente político passaram a ser judicializáveis.

O considerável crescimento do fenômeno da judicialização fez com que algumas questões de ampla repercussão política estejam sendo definidas pelo poder judiciário, e não mais pelas instâncias políticas tradicionais, como o congresso nacional e o poder executivo - em âmbito Federal e Estadual. Nesse cenário, os principais instrumentos de judicialização da política estão sendo as ações de controle de constitucionalidade.

Como exemplos de questões consideradas políticas que foram dirimidas pelo poder judiciário e particularmente pelo Supremo Tribunal Federal, por

\footnotetext{
1 Mestre em Ciência Jurídica pela Universidade do Vale do Itajaí (UNIVALI) - Advogada inscrita na OAB/SC 49.250. E-mail: crlasimon@gmail.com.

2 Doutora em Direito pela Università degli Studi di Roma - La Sapienza; Mestre em Estudos Medievais pela Pontifícia Università Antonianum. Professora no Programa de Mestrado e Doutorado em Ciência Jurídica da Universidade do Vale do Itajaí (UNIVALI) e na graduação em Direito do Centro Universitário Católica de Santa Catarina. E-mail: luciene.dalri@univali.br. O presente artigo se insere nas atividades de pesquisa do Programa de Mestrado e Doutorado em Ciência Jurídica, UNIVALI, em específico na linha de pesquisa em Constitucionalismo e Produção do Direito e no grupo de pesquisa em Estado, Constitucionalismo e Produção do Direito; e nas atividades do grupo de pesquisa Direito na aceleração da dinâmica social e as novas tecnologias, da Escola de Direito da Católica/SC em Joinville.
} 
meio de ações de controle de constitucionalidade, tem-se a criação do Conselho Nacional de Justiça, na Reforma do Judiciário (ADI 3367), o uso de células tronco embrionárias em pesquisas (ADI 3510/DF), a interrupção da gestação de fetos anencefálicos (ADPF 54/DF), as ações afirmativas e as quotas sociais e raciais (ADI 3330); a vedação ao nepotismo (ADC 12/DF e Súmula no 13 ) e a nãorecepção da Lei de Imprensa (ADPF 130/DF).

A amplitude das pesquisas sobre controle de constitucionalidade e legitimados de cunho federal não encontra continuidade, porém naqueles estaduais, por exemplo quanto à atuação dos governadores como sujeitos legitimados na judicialização da política.

Considerando essa lacuna, o presente artigo tem como objeto a atuação dos Governadores do estado de Santa Catarina, por meio de ações de Arguição de Descumprimento de Preceito Fundamental (ADPF), junto ao Supremo Tribunal Federal, desde sua criação, sob a Constituição da República Federativa do Brasil, de 1988. Busca-se verificar o efetivo uso que o chefe do poder executivo estadual tem dado às ADPFs e se esse tipo de ação pode ser considerado um instrumento viável na defesa dos interesses do estado de Santa Catarina.

Diante de tal contexto, evidencia-se a hipótese de que possa haver judicialização da política como instrumento de busca, em âmbito judicial, por resultados não alcançados por via eleitoral ou parlamentar, evidenciando que o fenômeno de judicialização não ocorre isolado de interesses sociais e econômicos centrais, que estruturam o sistema político. Bem como evidencia-se a possibilidade que as ações de Arguição de Descumprimento de Preceito Fundamental tenham se tornado instrumento governamental para ganhar visibilidade pública ou desviar as atenções em momentos políticos considerados não favoráveis.

Para tratar dos questionamentos trazidos nesse artigo, usa-se do método indutivo, com pesquisa bibliográfica e jurisprudencial. $\mathrm{O}$ artigo está dividido em 2 itens: o primeiro trata do sistema de controle de constitucionalidade brasileiro, em especial o controle concentrado, bem como, as teorias e definições acerca do fenômeno da judicialização.

O segundo trata das ações de Arguição de Descumprimento de Preceito Fundamental, especificamente, em que são coletados e analisados os dados obtidos no sítio do Supremo Tribunal Federal. Com isso pretende-se verificar de que forma esse tipo de ação está sendo usado, quais as matérias abarcadas bem como o grau de sucesso das citadas ações.

O presente trabalho se encerra com as considerações finais na qual evidencia-se o crescente uso desse tipo de ação pelos chefes do executivo estadual, da mesma maneira que se estabelece como um instrumento efetivo na defesa dos interesses do estado de Santa Catarina. 


\section{CONTROLE DE CONSTITUCIONALIDADEE JUDICIALIZAÇÃO DA POLÍTICA NO BRASIL}

A constituição é norma fundamental de um ordenamento jurídico, tendo como característica a sua imperatividade ${ }^{1}$. A supremacia constitucional garante que nenhuma norma inferior à constituição possa contrariá-la. Todas as normas constitucionais possuem a característica imperativa, não lhes sendo próprio sugerir, recomendar ou facultar o cumprimento do seu ditame. As normas constitucionais, em sua maior parte, materializam-se em normas cogentes, proibindo ou impondo determinado comportamento. Nesse sentido, é possível, portanto, violar a constituição por meio de uma ação, ou seja, realizando determinado ato que ela proíba, ou mediante a uma omissão, deixando de realizar algo que assim ela exija. ${ }^{2}$

Neste viés, os atos omissivos ou comissivos serão passíveis de controle de constitucionalidade e, esse controle pode ser exercido de forma preventiva ou repressiva. ${ }^{3}$ Neste artigo, pesquisa-se o controle repressivo, realizado em específico por meio do judiciário e de forma concentrada pelo Supremo Tribunal Federal.

O controle das normas visa garantir primeiramente a supremacia constitucional, para com isso garantir a estabilidade em última ratio de todo sistema organização jurídico-política do Estado. Assim como, visa impedir que normas contrárias ao texto constitucional coexistam. ${ }^{4}$

Esse processo de revisão é umas das formas democráticas de garantia da aplicação constitucional, conforme a interpretação que foi dada pelo poder constituinte, não se admitindo qualquer lei ou ato em desconformidade com essa interpretação. Nesse caso, aplicar-se-á o controle necessário para restabelecer a legalidade, nos termos em que ressalta Bonavides:

O órgão legislativo, ao derivar da Constituição sua competência, não pode obviamente introduzir no sistema jurídico leis contrárias às disposições constitucionais: essas leis se reputariam nulas, inaplicáveis, sem validade, inconsistentes com a ordem jurídica estabelecida $[\ldots]^{5}$

No Brasil, a Constituição Federal definiu em seu artigo 103 o rol de legitimados para propositura de ações de controle de constitucionalidade ${ }^{6}$, dentre os quais consta expressamente o "Governador de Estado ou do Distrito Federal". Posteriormente, a lei n. 9.882/1999 em seu art. $2^{\circ}$, I, combinado com o art. 12-A, da lei n. 9.868/1999, estabeleceu que os legitimados para propor ação direta de constitucionalidade e ação declaratória de constitucionalidade também o são para propor arguição de descumprimento de preceito fundamental. 
De outo lado, o artigo o art.102 da Constituição Federal estabeleceu o Supremo Tribunal Federal como guardião da Constituição. Nesse viés, cabe destacar a alta responsabilidade política, social e jurídica que a Constituição reservou ao Tribunal.

A força normativa da Constituição da República e o monopólio da última palavra, pelo STF, em matéria de interpretação constitucional. $\mathrm{O}$ exercício da jurisdição constitucional - que tem por objetivo preservar a supremacia da Constituição - põe em evidência a dimensão essencialmente política em que se projeta a atividade institucional do STF, pois, no processo de indagação constitucional, assenta-se a magna prerrogativa de decidir, em última análise, sobre a própria substância do poder. No poder de interpretar a Lei Fundamental, reside a prerrogativa extraordinária de (re)formulála, eis que a interpretação judicial acha-se compreendida entre os processos informais de mutação constitucional, a significar, portanto, que "A Constituição está em elaboração permanente nos Tribunais incumbidos de aplicá-la". Doutrina. Precedentes. A interpretação constitucional derivada das decisões proferidas pelo STF - a quem se atribuiu a função eminente de "guarda da Constituição" (CF, art. 102, caput) - assume papel de essencial importância na organização institucional do Estado brasileiro, a justificar o reconhecimento de que o modelo político-jurídico vigente em nosso país confere, à Suprema Corte, a singular prerrogativa de dispor do monopólio da última palavra em tema de exegese das normas inscritas no texto da Lei Fundamental. [ADI 3.345, rel. min. Celso de Mello, j. 25-8-2005, P, DJE de 20-8-2010.] (grifo nosso). ${ }^{7}$

A medida em que mais direitos foram constitucionalizados, bem como a via judicial foi estabelecida como meio de garantí-los, a expansão do poder judiciário foi inevitável. Cada vez mais os tribunais foram chamados a se manifestar sobre praticamente todas as questões da sociedade moderna, ao ponto de se ter a denominada judicialização.

A judicialização ${ }^{8}$ em si é um fenômeno em que se constata o acionamento do poder judiciário para a resolução de conflitos. Com base em Tate, pode-se dizer que "judicialização é a reação do Judiciário frente à provocação de um terceiro, é o ato de acessar o poder Judiciário". A judicialização da política, por sua vez, pode ser definida como espécie do gênero judicialização.

A literatura que se ocupa do tema no Brasil, adotou a definição dada por Tate e Vallinder, em que judicialização da política é "o fenômeno que significa o deslocamento do polo de decisão de certas questões que tradicionalmente cabiam aos poderes Legislativo e Executivo para o âmbito do Judiciário". ${ }^{10}$

Indo além, Tate e Vallinder ao analisarem o tema, perceberam que mesmo sob um ambiente muito favorável e de condições que o facilitem, o desenvolvimento 
atual da judicialização da política exige que os juízes tenham as atitudes pessoais e as preferências políticas ou os valores apropriados, especialmente em relação aos valores de outros tomadores de decisão. Em outras palavras, em condições favoráveis, a judicialização da política se desenvolve principalmente porque os juízes decidem que devem participar na elaboração de políticas (policy-making), substituindo as soluções de outras instituições por soluções próprias. ${ }^{11}$

Para Barroso, a judicialização que ocorre no Brasil, especificamente, não depende de vontade dos atores judiciais, pois o Tribunal é provocado e não pode furtar-se de dar uma resposta, deslocando temas que tradicionalmente eram apreciados na esfera política, seja pelo poder executivo ou pelo poder legislativo, para o campo jurisdicional devido à vários fatores. ${ }^{12}$

\section{ANÁLISE DAS AÇÕES DE ARGUIÇÃO DE DESCUMPRIMENTO DE PRECEITO FUNDAMENTAL}

A Arguição de Descumprimento de Preceito Fundamental - ADPF, foi prevista no texto constitucional, inicialmente no parágrafo único do art. 102 da Constituição Federal de 1988, que posteriormente se converteu em $\$ 1^{\circ}$ pela Emenda Constitucional n. 3 de março de $1993^{13}$, somente vindo a ser regulamentada em dezembro de 1999, por meio da lei n. 9.882, que dispôs sobre seu processamento e julgamento. ${ }^{14}$

Porém, parte da doutrina $\mathrm{a}^{15}$ critica a regulamentação dada pela referida lei, principalmente pelo que deixou de regulamentar, como por exemplo, o alcance específico que a ação teria, tema que fomentava amplos debates doutrinários. ${ }^{16}$

Nesse sentido, difícil é a delimitação ou a conceituação a priori do objeto da ação, ou melhor, do significado da locução "preceitos fundamentais da Constituição passiveis de lesão ou grave ameaça" que justifiquem a propositura da arguição de descumprimento. ${ }^{17}$

Como a Constituição e a lei não especificam o sentido da expressão "preceito fundamental", coube à doutrina e à jurisprudência a tentativa de realizar tal tarefa. ${ }^{18}$ Desse modo, a delimitação do conceito de Preceito Fundamental se baseia nas matérias arguidas nas ações que o Supremo Tribunal Federal acolhe.

Nessa perspectiva, Barroso preceitua que embora esses conceitos indeterminados conservem fluidez que lhes é própria, há um determinado grupo de normas que deve estar compreendido pelo entendimento de preceitos fundamentais, como "um conjunto de disposições constitucionais que, embora ainda não conte com uma definição precisa, certamente inclui com as decisões sobre a estrutura básica do Estado, o catálogo de Direitos fundamentais e os chamados princípios sensíveis". ${ }^{19}$ 
Desse modo, enfatiza-se que o parágrafo único da lei n. 9.882/99 dispõe que caberá arguição de descumprimento de preceito fundamental quando for relevante o fundamento da controvérsia de lei ou ato normativo constitucional, estadual ou municipal.

Assim, a ADPF abarca temas referentes à todas as esferas normativas da federação brasileira, diferentemente do que ocorre com as demais ações de controle de constitucionalidade por via concentrada. E, o principal ponto que diferencia essa ação das demais, é o princípio da subsidiariedade ao qual está adstrita. Dessa forma, o que não for compreendido pela ADI ou ADC poderá ser objeto de exame no âmbito da ADPF.

As ADPFs somente começaram a ser propostas no ano 2000, o que decorre, justamente, de sua regulamentação no ano de 1999. Então, no primeiro ano seguinte a sua regulamentação, foram propostas inicialmente 10 ações. Em razão das dificuldades em se estabelecer os balizamentos para a utilização da ADPF, acreditava-se não ser esta ação tão comum entre os Governadores.

Nesse viés, coaduna a afirmação de Barroso, que a regra no sistema de controle concentrado no Brasil é a "fiscalização incidental difusa"20. No entanto, a lei n. 9.882/99 reforça a tendência de ampliação do papel da jurisdição constitucional concentrada, que tem se desenvolvido nos últimos anos no cenário brasileiro. ${ }^{21}$

A ação de arguição de descumprimento de preceito fundamental apesar de tardiamente inserida no complexo sistema de controle de constitucionalidade brasileiro ganhou força e se estabeleceu como uma forma importante de acesso ao controle concentrado da jurisdição nacional.

Em pesquisa realizada em 2013, evidenciou-se que das então 274 ADPFs que tramitavam no Supremo Tribunal Federal, os três maiores demandantes eram as confederações sindicais e entidades de classe de âmbito nacional, tendo apresentado $28,8 \%$ das ações; os partidos políticos com representação no congresso nacional, com $28,1 \%$ e os governadores de estados e do Distrito Federal, com $15,3 \%$ das ações. ${ }^{22}$

Os governadores de estados e do Distrito Federal estavam então entre os que mais demandavam na corte, mesmo considerando a necessidade de comprovação de pertinência temática da pretensão formulada na declaração de descumprimento. ${ }^{23}$

Em 2019, as ADPFs chegaram ao número de 635 ações, das quais 154 são provenientes da Presidência da República, 66 foram propostas pelo Procurador (ou a Procuradoria) Geral da República e 63 pelo Congresso Nacional. Percebe-se também que essa ação vem sendo muito utilizada por pequenos partidos políticos, como o Partido Socialismo e Liberdade (PSOL) e a Rede Sustentabilidade, respectivamente com 19 e 14 ações propostas. ${ }^{24}$ 
Os governadores apresentaram menor atuação como propositores, muito embora observe-se que os chefes do poder executivo do estado da Paraíba e do Piauí ainda figuram entre os principais demandantes nacionais, respectivamente com 18 e 15 ações proposta no total. ${ }^{25}$

Com relação às ações de arguição de descumprimento de preceito fundamental impetradas pelos governadores de Santa Catarina, a lista é enxuta com apenas 6 ações protocoladas. Muito embora a primeira ação tenha sido apresentada em 2007, as demais foram todas posteriores ao ano de 2017. ${ }^{26}$ Salienta-se que as ADPFs em sua maioria, quatro das seis, foram ajuizadas pelo Governador Raimundo Colombo, no final de seu mandato que corresponde ao período de 2011 a 2018. Colombo foi o governador que mais se utilizou desse tipo de ação entre os chefes do executivo estadual catarinense, muito embora não tenha sido o único.

A primeira ADPF proposta pelo governante catarinense foi a ADPF 111, de 2007, que visava impugnar decisão do Tribunal de Justiça do Estado de Santa Catarina que declarou a inconstitucionalidade de lei municipal.

O Ministro Ayres Britto, não conheceu da arguição fundamentando-se na jurisprudência do próprio Supremo Tribunal Federal:

8. [...] Supremo Tribunal vem admitindo o manejo de recurso extraordinário contra decisão que julga representação de inconstitucionalidade (a ADI estadual, prosaicamente falando) quando os dispositivos da Constituição Estadual, apontados como violados, são de repetição obrigatória da Constituição Federal (RE 302.803- AgR, Rel. Min. ELLEN GRACIE; AI 486.965-AgR, Rel. Min. EROS GRAU; entre outros).

E o fato é que, no caso, a Corte local declarou inválida a Lei blumenauense no 5.824/2001, por divisar ofensa a normas da Constituição Estadual que foram compulsoriamente absorvidas da Lei Maior da República. Nesse fluxo de ideias, infere-se que a decisão a ser tomada pelo Supremo Tribunal Federal, ao julgar um eventual recurso extraordinário contra o pronunciamento do TJ/ SC, não terá os normais efeitos inter partes, inerentes a qualquer processo de índole subjetiva. Terá, isto sim, a mesma eficácia do acórdão prolatado pelo Tribunal de Justiça quando do julgamento da representação de inconstitucionalidade. ${ }^{27}$

Com relação aos temas abarcados, observa-se que as ações propostas pelos governantes catarinenses versam sobre matéria relativa a tributos, verbas trabalhistas, separação de poderes ou pacto federativo.

Observa-se assim que a ADPF 501 foi proposta contra súmula editada pelo Tribunal Superior do Trabalho - TST, tratando, desse modo, de matéria trabalhista. Aduz a ADPF em questão, que a aplicação da Súmula 450 do TST, 
quando em questão de relações jurídicas trabalhistas titularizadas por empregados públicos vinculados às empresas públicas, detém o potencial de geração de expressivos prejuízos às finanças públicas estaduais (matéria de suma importância para o equilíbrio fiscal das contas).

Alega, ainda, que a referida súmula macula os preceitos fundamentais consubstanciados no princípio da Separação de Poderes. Essa ADPF teve seu segmento negado, sem resolução do mérito. Entendeu assim o Min. Alexandre de Moraes:

[...] A Arguição de Descumprimento de Preceito Fundamental de que ora se cuida não suporta as condições necessárias ao seu regular processamento, ausente ato do Poder Público com conteúdo que possa conduzir a efetiva lesão a preceito fundamental. Isso porque "enunciados de Súmula [que] nada mais são senão expressões sintetizadas de entendimentos consolidados na Corte" (ADPF 80 AgR, Rel. Min. EROS GRAU, Pleno, Dj de 10/8/2006). Na mesma linha de compreensão o decidido na ADPF 152 (Rel. Min. CEZAR PELUSO, Decisão monocrática, Dê de 17/9/2008). Confira-se: (...) 2. É caso de extinção anômala do processo. Carece de interesse jurídico arguição de descumprimento de preceito fundamental contra enunciado de súmula de orientação jurisprudencial, conforme entendimento já manifestado pela Corte, em caso análogo ( ... ) Ademais, o cabimento da ADPF somente se mostra viável desde que haja a observância do princípio da subsidiariedade, segundo o qual se mostra incontornável o esgotamento de todas as vias possíveis para superação da lesão ou a ameaça a preceitos fundamentais ou a verificação, ab initio, de sua inutilidade para a preservação do preceito (ADPF 186/DF, Rel. Min. RICARDO LEWANDOWSKI, DJe de 20/10/2014). Caso os mecanismos utilizados de maneira exaustiva mostrem-se ineficazes, será cabível o ajuizamento da arguição. Não é, porém, o que ocorre na presente Arguição,[...] Ante o exposto, com apoio nos artigos $4^{\circ}$, caput, da Lei $n^{\circ} 9.882 / 1999 ; 330$, incisos I e III, 485, incisos I, IV e VI, do Código de Processo Civil de 2015; e 21, $\$ 1^{\circ}$, do Regimento Interno do SUPREMO TRIBUNAL FEDERAL, NEGO SEGUIMENTO à Arguição de Descumprimento de Preceito Fundamental 501, devendo ser EXTINTO, sem resolução de mérito, o processo. Publique-se. Brasília, 19 de dezembro de 2017. Ministro Alexandre de Moraes Relator Documento assinado digitalmente. (ADPF 501, Relator(a): Min. ALEXANDRE DE MORAES, julgado em 19/12/2017, publicado em PROCESSO ELETRÔNICO DJe-018 DIVULG 31/01/2018 PUBLIC 01/02/2018) ${ }^{28}$ (grifo nosso)

Nesse viés, é possível perceber que segundo as decisões reiteradas do Supremo Tribunal há fixação do principio da subsidiariedade para o uso da referida ação. Caso os demais mecanismos utilizados de maneira exaustiva mostrem-se ineficazes, então será cabível o ajuizamento da arguição. Denota-se 
que a matéria tratada na referida ação possui grande relevância, mas acaba por ser deixada à margem de resolução por não se entender ser este o instrumento correto para a sua resolução.

De outra parte, a ADPF 523 possui 22 Governadores de estados mais o do Distrito Federal como requerentes, demandando em face do Presidente da República, em matéria tributária relativa à instituição de contribuição social (genericamente entendidas) que não é partilhada com os entes federados, contrariando assim art. 157, inciso II da CF/88. ${ }^{29}$

Aduzem os autores da arguição que o preceito fundamental violado nesse caso é o princípio federativo, pois trata-se de cláusula pétrea e a doutrina majoritária concorda que a Constituição Federal de 1988 fortaleceu o federalismo e, então não é possível se admitir ato do poder público que fira esse preceito fundamental. Contudo, não há decisão nesse caso, pois a demanda aguarda julgamento.

Adiante, tem-se a Arguição Descumprimento de Preceito Fundamental ADPF 535, com pedido de liminar ajuizada pelo Governador do Estado de Santa Catarina, em que se busca suspender a eficácia da lei n. 3.851/2012, do Município de Mafra, que dispõe sobre o comércio de artigos de conveniência e a prestação de serviços de utilidade pública e farmácias e drogarias, a qual teria afrontado o princípio do pacto federativo. Novamente tem-se matéria tributária-fiscal como mérito da demanda. O processo se encontra em tramitação, ainda sem decisão definitiva sobre o mérito.

$\mathrm{Na}$ ADPF 542 observa-se também pedido de liminar, por parte do governador diante da execução de sentença que tramita na $7^{\mathrm{a}}$ vara do trabalho de Florianópolis, tendo como executada a Companhia integrada de desenvolvimento agricola de Santa Catarina - CIDASC. A ação versa sobre ordem judicial de sequestro de valores das contas da Companhia. Aduz o Governador que este ato ofende preceitos fundamentais de extrema relevância e importância no que respeita à separação de poderes, ao controle financeiro e orçamentário do Estado de Santa Catarina e ao regime constitucional dos precatórios, notadamente com a inclusão do art. 103 ao Ato das Disposições Constitucionais Transitórias pela Emenda Constitucional 94, de 15 de dezembro de 2016. O processo ainda está em tramitação, tendo obtido medida liminar para suspender o sequestro dos valores até julgamento do mérito.

Por fim, a ADPF n. 587, trata de matéria de direito processual civil e do trabalho, mas apesar de inicialmente parecer se tratar de matéria diversa das ADPFs anteriores, essa impressão inicial não se confirma. Esmiuçando a referida ação percebe-se tratar-se de matéria fiscal embutida nas demais matérias suscitadas, como se verá a seguir. O governador de Santa Catarina, Carlos Moisés da Silva, ajuizou a arguição de descumprimento de preceito fundamental, acima referida, para questionar decisões da justiça do trabalho que resultaram em bloqueio, penhora e liberação de valores de contas de empresas públicas estaduais 
para pagamento de indenizações trabalhistas à revelia do regime de precatórios visto no artigo 100 da Constituição Federal.

O governador pede liminar para suspender os efeitos das decisões judiciais até que o mérito das ADPFs seja julgado, quando esperam que o STF declare a impossibilidade de constrição sobre tais contas.

Segundo o governador catarinense, as decisões judiciais violam preceitos fundamentais, como o princípio da independência e harmonia dos poderes, os princípios e regras da atividade financeira e orçamentária estatal, o princípio federativo, a garantia de pagamentos devidos pela fazenda pública em ordem cronológica de apresentação de precatórios, o princípio da igualdade dos credores do estado e o princípio da continuidade dos serviços públicos.

Afirma o governador catarinense que:

Embora a EPAGRI-SC tenha recorrido dessas decisões, alegando que a ela deve se aplicar o regime de precatórios, reiteradas decisões têm negado o pleito da empresa, sob o argumento de que, por se tratar de empresa pública, a ela deve se aplicar o regime jurídico próprio das empresas privadas, desconsiderando o fato de que a EPAGRI-SC não exerce atividade econômica em sentido estrito. ${ }^{30}$

O governador acrescenta, ainda, que as constrições nas contas da empresa ultrapassam R $\mathrm{R}, 4$ milhões, o que tem prejudicado o desempenho de suas atividades. Todavia, como essa arguição foi proposta em maio do corrente ano de 2019, ainda se encontra em tramitação e, ao que parece, lhe será dado segmento pelo tribunal, contudo não há até o momento nenhuma decisão indicando o norte do entendimento.

\section{CONSIDERAÇÕES FINAIS}

O controle de constitucionalidade das normas no Brasil pode ser exercido por meio de diferentes vias, nos três poderes. A forma repressiva e concentrada em âmbito federal é exercida pelo Supremo Tribunal Federal a partir de provocação, por meio de ações específicas de controle de constitucionalidade (genericamente entendidas). Se as ações diretas de inconstitucionalidade e as ações declaratórias de constitucionalidade têm sido de clara instrumentalização para o debate político, as arguições de descumprimento de preceito fundamental, por sua tardia regulamentação, bem como natureza subsidiária e menos restrita teve uma aparição posterior e mais tímida, no campo da judicialização da política.

Considerando que o conceito mínimo da judicialização da política significa a transferência de decisões do campo parlamentar ou executivo para o campo judicial, colhe-se como desdobramentos da judicialização da política, 
o aumento da demanda judicial e a necessidade da policy-making, não se confundindo, porém, com o ativismo judicial.

A judicialização da política, junto ao Supremo Tribunal Federal, por meio de Arguições de Descumprimento de Preceito Fundamental tem encontrado entes atuantes dentro e fora do âmbito do poder executivo e daquele legislativo, com particular destaque à intensidade de atuação de pequenos partidos políticos que muitas vezes usam do espaço judicial para fazer ouvir seus interesses.

O mesmo ocorre com os governadores de estado, e particularmente com o governador do estado de Santa Catarina, que desde 2007 vem atuando por meio desse tipo de ação. Analisando as ações propostas, foi possível verificar que as matérias tratadas são de grande interesse para o estado, tratando de questões relativas a tributos, verbas trabalhistas, separação de poderes ou pacto federativo, abarcando conflitos originários de esferas federais, estaduais e municipais. É possível observar também que os posicionamentos assumidos pelos governadores não implicam em desvirtuar a própria responsabilidade administrativa, mas sim em dar efetividade à ela; e que as arguições de descumprimento de preceito fundamental podem ser consideras e tem sido propostas como um instrumento viável para a defesa dos interesses estaduais, principalmente, pela subsidiariedade a qual essa via de ação está atrelada, não tornando-se uma barreira processual, mas uma possibilidade para demandar questões que não sejam abarcadas pelas demais ações específicas.

\section{NOTAS}

1 BARROSO, 2012, p. 53

2 BARROSO, 2012, p. 53.

3 MENDES, 2018, p.1157.

4 Portanto, haverá inconstitucionalidade, pois, quando uma norma estiver em conflito com a Constituição, comprometendo a supremacia das normas constitucionais, e, por derradeiro, da própria validade do ordenamento jurídico. Nesse sentido ratifica Cunha Júnior: "A ideia de inconstitucionalidade, portanto, decorre do princípio da hierarquia das normas jurídicas, em vista do qual as normas inferiores haurem seu fundamento de validade nas normas superiores. Como na ordem jurídica interna a Constituição é a norma jurídica suprema, a matriz de todas as outras manifestações normativas do Estado, qualquer norma que a venha diretamente contrariar é tida como inconstitucional, expondo-se à invalidação". CUNHA JUNIOR, Dirley da. Controle de Constitucionalidade - teoria e prática. p.186.

5 BONAVIDES, 2015, p. 303-304.

6 BRASIL. Constituição da República Federativa do Brasil. Brasília: Senado, 1988. Artigo 103 da CFRB/88. (De acordo com Redação dada pela Emenda Constitucional no 45, de 2004).

7 BRASIL. Supremo Tribunal Federal. A Constituição e o Supremo. 6. ed. atual até a EC 99/2017. Brasília STF, Secretária de documentação, 2018. Disponível em: http;//www.stf.jus.br/portal/ constituição/>. Acesso em: 28 abr. 2019.

8 Os autores Tate e Vallinder em sua obra The Global Expansion of Judicial Power: The Judicialization of Politics, fizeram um estudo profundo sobre o tema. A abordagem de Tate e Vallinder, apesar de 
focada no sistema norte-americano do common-law, foi introduzida no cenário brasileiro pelos estudos de Castro (1993), Teixeira (1997) e Vianna et.al (1999 e 2007), tendo esses autores justificado o movimento da Judicialização da Política pelo crescente aumento das ações judiciais, em especial as ações diretas de inconstitucionalidade.

9 Este Conceito Operacional foi elaborado a partir de TATE; VALLINDER, 1995, p.13.

10 TATE; VALLINDER, 1995, p.13.

11 TATE; VALLINDER, 1995, p.33.

12 O Ativismo Judicial distingue-se da judicialização da política, por ser conforme Barroso "uma atitude, a escolha de um modo específico proativo de interpretar a Constituição" expandindo seu sentido e alcance além do que está estabelecido, interpreta-se além do texto constitucional. BARROSO, 2012, p. 23-32. Disponível em: https://www.e-publicacoes.uerj.br/index.php/synthesis/ article/view/7433/5388. Acesso em: 10 abr. 2019. Ver também CAMPOS, 2015, p. 185.

13 O parágrafo $1^{\circ}$ conservou a mesma redação: "A arguição de descumprimento de preceito fundamental, decorrente desta Constituição, será apreciada pelo Supremo Tribunal Federal, na forma da lei." BRASIL. Constituição da República Federativa do Brasil. Brasília: Senado, 1988.

14 BARROSO, 2012, p.305.

15 TAVARES; ROTENBURG, 2001. FERREIRA FILHO, 2000. RÊGO, 2003.

16 BARROSO, 2012, p.306.

17 MENDES, 2007, p. 80.

18 BARROSO, 2012, p.311.

19 BARROSO, 2012, p.313.

20 Nesse sentido, reforçando a afirmação de Barroso é a passagem do voto do Min. Moreira Alves, no julgamento de questão de ordem da ADC 1: "Este (o controle difuso), apesar da expansão dada ao controle concentrado [...], continua a ser regra, só não podendo ser utilizado legitimamente com relação aos atos normativos que, anteriormente, tenham sido declarados, pelo controle concentrado em abstrato, constitucionais ou inconstitucionais, ou que haja tido sua execução suspensa pelo Senado quando a declaração de inconstitucionalidade resulte do controle difuso exercido pelo Supremo Tribunal Federal." (RTJ, 157:371, 1996, rel. Min. Moreira Alves, p. 383-4) (grifo acrescido para melhor compreensão). BRASIL. Supremo Tribunal Federal.

21 BARROSO, 2012, p.307.

22 Dados atualizados até 03 de dezembro de 2019 e disponibilizados em pesquisa realizada por meio da ferramenta de busca disponível em: http://www.stf.jus.br/portal/peticaoInicial/ pesquisarPeticaoInicial.asp.

23 A propósito o voto do Min. Relator Marco Aurélio: “AÇÃO DIRETA DE INCONSTITUCIONALIDADE - PERTINENCIA. Tratando-se de impugnação de ato normativo de Estado diverso daquele governado pelo requerente, impõe-se a demonstração do requisito "pertinência" [...]" (ADI 902 MC, Relator: Min. MARCO AURÉLIO, Tribunal Pleno, julgado em 03/03/1994, DJ 22-04-1994 PP-08941 EMENT VOL-01741-01 PP-00199). Disponível em: http:// stf.jus.br/portal/jurisprudencia/listarJurisprudencia.asp?s1=\%28ADI\%24\%2ESCLA\%2E+E+902\% 2ENUME\%2E\%29+OU+\%28ADI\%2EACMS\%2E+ADJ2+902\%2EACMS\%2E\%29\&base=baseAco rdaos\&url=http://tinyurl.com/b6378uq. Acesso em:10 jun. 2019.

24 Foram considerados processos finalizados após 2000 e em tramitação. Fonte: Estatísticas STF.

25 Foram considerados processos finalizados após 2000 e em tramitação. Fonte: Estatísticas STF.

26 Ver ADPFs n. 111, 501, 523, 535, 542 e 587. 
27 STF. ADPF 111/SC. Rel.: Min. AYRES BRITTO. 27/9/2007, decisão monocrática. DJe 116, 3 out. 2007. Disponível em: http://portal.stf.jus.br/processos/downloadPeca.asp?id=310190585\&ext=.pdf. Acesso em: 30 nov. 2019.

28 BRASIL. Supremo Tribunal Federal. Decisão Monocrática. ADPF 501. Propositor: Governador do Estado de Santa Catarina. Relator: Ministro Relator Alexandre Moraes. Diário Oficial da União. Brasília. 19 de dezembro de 2017. Disponível em: <http://redir.stf.jus.br/estfvisualizadorpub/jsp/ consultarprocessoeletronico $/$ ConsultarProcessoEletronico.jsf?seqobjetoincidente $=5322450>$. Acesso em: 01 jun. 2019.

29 BRASIL. Supremo Tribunal Federal. ADPF 523. Propositor Governador do Estado de Minas Gerais e outros. Disponível em: http://portal.stf.jus.br/processos/detalhe.asp?incidente $=5485462$. Acesso em:29 nov. 2019.

30 BRASIL. Supremo Tribunal Federal. ADPF 587. Propositor: Governador do Estado de Santa Catarina. Relator: Celso de Melo. Disponível em: https://portal.stf.jus.br/processos/detalhe. asp?incidente $=5704665$. Acesso em: 30 nov. 2019.

\section{REFERÊNCIAS}

BARROSO, Luís Roberto. O Controle de Constitucionalidade no direito brasileiro: exposição sistemática da doutrina e análise crítica da jurisprudência. 6.ed. ver. e atual. São Paulo: Saraiva, 2012.

BARROSO, Luiz Roberto. Judicialização, ativismo Judicial e Legitimidade Democrática. Revista (SYN)THESIS v. 5, n. 1, 2012. p. 23-32. Disponível em: https://www.epublicacoes.uerj.br/index.php/synthesis/article/view/7433/5388. Acesso em: 10 abr. 2019.

BONAVIDES, Paulo. Curso de Direito Constitucional. 30 ed. São Paulo: Malheiros, 2015.

BRASIL. Supremo Tribunal Federal. A Constituição e o Supremo. 6. ed. atual até a EC 99/2017. Brasília STF, Secretária de documentação, 2018. Disponível em: http;//www.stf. jus.br/portal/constituição/>. Acesso em: 28 abr. 2019.

BRASIL. Supremo Tribunal Federal. Decisão Monocrática. ADPF 501. Propositor: Governador do Estado de Santa Catarina. Relator: Ministro Relator Alexandre Moraes. Diário Oficial da União. Brasília. 19 de dezembro de 2017. Disponível em: <http://redir.stf.jus.br/estfvisualizadorpub/jsp/consultarprocessoeletronico/ ConsultarProcessoEletronico.jsf?seqobjetoincidente $=5322450>$. Acesso em: 01 jun. 2019.

BRASIL. Supremo Tribunal Federal. Decisão Monocrática. ADPF 111. Propositor: Governador do Estado de Santa Catarina. Relator: Ministro AYRES BRITTO. 27/9/2007, decisão monocrática. DJe 116, 3 out. 2007. Disponível em: http://portal.stf.jus.br/ processos/downloadPeca.asp?id=310190585\&ext=.pdf. Acesso em: 30 nov. 2019.

BRASIL. Supremo Tribunal Federal. ADPF 523. Propositor Governador do Estado de Minas Gerais e outros. Relator: Ministra Rosa Weber. Disponível em: http://portal.stf.jus. br/processos/detalhe.asp?incidente=5485462. Acesso em: 29 nov. 2019. 
BRASIL. Supremo Tribunal Federal. Decisão Monocrática. ADPF 535. Propositor: Governador do Estado de Santa Catarina. Relator: Ministro Ricardo Lewandowski. Disponível em: https://portal.stf.jus.br/processos/detalhe.asp?incidente $=5512840$. Acesso em: 29 nov. 2019.

BRASIL. Supremo Tribunal Federal. ADPF 587. Propositor: Governador do Estado de Santa Catarina. Relator: Celso de Melo. Disponível em: https://portal.stf.jus.br/ processos/detalhe.asp?incidente $=5704665$. Acesso em: 30 nov. 2019.

BRASIL. Supremo Tribunal Federal. Disponível em: http://portal.stf.jus.br/processos/ listarPartes.asp?termo=governador\%20de\%20Santa\%20Catarina. Acesso em: $15 \mathrm{de} \mathrm{fev.}$ 2018.

CAMPOS, Carlos Alexandre de Azevedo. Supremo Tribunal Federal, política e democracia In: SARMENTO, Daniel. Jurisdição constitucional e política. 1.ed. Rio de Janeiro: Forense, 2015.

CAPPELLETTI, Mauro. O Controle Judicial De Constitucionalidade Das Leis No Direito Comparado. 2.ed. Tradução Aroldo Plínio Gonçalves. Porto Alegre: Fabris, 1984.

CUNHA JUNIOR, Dirley da. Constituição - teoria e prática. 8.ed. Salvador: Juspodvim, 2016.

FERREIRA FILHO, Manoel Gonçalves. O sistema constitucional brasileiro e as recentres inovações no controle de constitucionalidade. RDA, Rio de Janeiro, 220:1-17, abr.-jun. 2000.

MENDES, Gilmar Ferreira. Arguição de descumprimento de preceito fundamental: comentários a lei 9.882/99. São Paulo: Saraiva, 2007.

MENDES, Gilmar Ferreira; BRANCO, Paulo G. Gonet. Curso de Direito Constitucional. 13. ed. São Paulo: rev. e atual, 2018.

MORAES, Alexandre de. Direito Constitucional. 9. ed. São Paulo: Atlas, 2001.

PASOLD, Cesar Luiz. Metodologia da pesquisa jurídica: teoria e prática 14 ed. ver., atual. e ampl. Florianópolis: Empório Modara, 2018.

RÊGO, Bruno Noura de Moraes. Arguição de descumprimento de preceito fundamental. Porto Alegre: Sérgio Antônio Fabris, 2003.

TAVARES, André Ramos; ROTHENBURG, Walter Claudius. (Org.). Argüição de descumprimento de preceito constitucional fundamental: análises à luz da Lei n. 9882/99. São Paulo: Atlas, 2001.

TATE, Chester Neal; VALLINDER, Torbjorn. The Global Expansion of Judicial Power: The Judicialization of Politics. New York: New York University, 1995. 


\title{
JUDICIALIZAÇÃO DA POLÍTICA: A ATUAÇÃO DOS GOVERNADORES DO ESTADO DE SANTA CATARINA POR MEIO DE AÇÕES DE ADPF JUNTO AO SUPREMO TRIBUNAL FEDERAL
}

\begin{abstract}
Resumo
O presente artigo analisa a atuação dos governadores do estado de Santa Catariana por meio das ações de Arguição de Descumprimento de Preceito Fundamental, junto ao Supremo Tribunal Federal, questionando a instrumentalização desse tipo de ação e a sua viabilidade na defesa dos interesses do estado de Santa Catarina. Para a análise, o trabalho foi dividido em dois títulos: o primeiro aborda o sistema de controle de constitucionalidade concentrado brasileiro, bem como, as teorias e definições acerca do fenômeno da judicialização; o segundo título discorre, especificamente, sobre as ações de Arguição de Descumprimento de Preceito Fundamental, em que são coletados e analisados os dados obtidos no sítio do Supremo Tribunal Federal, quanto à atuação dos governadores catarinenses. Com isso verificou-se, por meio do método indutivo, de que forma esse tipo de ação esta sendo usado, quais as matérias atacadas, bem como o grau de sucesso judicial. Nas considerações finais evidencia-se que diante dos casos analisados, a ADPF pode ser considerada e tem sido usada como um instrumento viável para a defesa dos interesses estaduais, principalmente devido à subsidiariedade a qual está atrelada e aos interesses defendidos por meio desse tipo de ação junto ao Supremo Tribunal Federal.
\end{abstract}

Palavras-chave: Arguição de Descumprimento de Preceito Fundamental. Controle de Constitucionalidade. Judicialização da Política. 


\title{
POLICY JUDICIALIZATION: THE PERFORMANCE OF THE GOVERNORS OF THE STATE OF SANTA CATARINA THROUGH ADPF ACTIONS WITH THE SUPREME FEDERAL COURT
}

\begin{abstract}
The present article analyzes the job performance of the state governors of Santa Catarina through the actions of 'Arguição de Descumprimento de Preceito Fundamental', at the Supreme Federal Court, questioning the instrumentalization of this kind of action and its feasibility in defending the interests of the state of Santa Catarina. For the analysis, the article was divided into two titles: the first one deals with the Brazilian concentrated constitutionality control system, as well as the theories and definitions regarding the phenomenon of Judicialization; The second title corresponds specifically with the 'Arguição de Descumprimento de Preceito Fundamental' actions in which the data obtained from the Supreme Court's website are gathered and analyzed in connection with the conducts presented by the Santa Catarina state governors. As a result it was verified, by using the inductive method, the way this type of action is being used, which were the topics impelled, as well as what was the rate of judicial success. It is remarked in the final considerations that, in view of the cases analyzed, the ADPF has been used and can be considered, as an applicable instrument for the preservation of state interests, mainly due to the subsidiarity to which it is linked and the interests defended protected through this type of action within the Federal Supreme Court.
\end{abstract}

Keywords: Arguição de Descumprimento de Preceito Fundamental. Constitutionality Control. Judicialization of Politics. 